\title{
Correction to: The effect of bank branch closures on new firm formation: the Swedish case
}

\section{Cynthia Sin Tian $\mathrm{Ho}^{1}$ (i) $\cdot$ Björn Berggren ${ }^{1}[$}

Published online: 22 October 2021

(c) Springer-Verlag GmbH Germany, part of Springer Nature 2021

\section{Correction to: The Annals of Regional Science (2020) 65:319-350 https://doi.org/10.1007/s00168-020-00986-4}

The following are the typo errors I have found:

A typo error on page 327 of the published paper:

"Detailed calculations for the variables TheilIndex, IncomeGrowth, and ChangeHP can be found in the appendix"

The correct version should be:

"Detailed calculations for the variables TheilIndex, SpecIndex, and IncomeGrowth can be found in Appendix"

Another typo error on page 334 of the published paper:

"All the dependent and independent variables are logged except for IncomeGrowth to make the distribution of the transformed variables more normal. The IncomeGrowth variable is not logged because it includes negative values."

The correct version should be:

"All the dependent and independent variables are logged except for ChangeHP to make the distribution of the transformed variables more normal. The ChangeHP variable is not logged because it includes negative values."

Publisher's Note Springer Nature remains neutral with regard to jurisdictional claims in published maps and institutional affiliations.

The original article can be found online at https://doi.org/10.1007/s00168-020-00986-4.

Cynthia Sin Tian Ho

cstho@kth.se

1 Department of Real Estate and Construction Management, KTH - The Royal Institute of Technology, Stockholm, Sweden 